\title{
Three-cycle University studies in metrology - An innovative development approach
}

\author{
Marija Cundeva-Blajer \\ Ss. Cyril and Methodius University, Faculty of Electrical Engineering and Information Technologies, ul. Ruger Boskovic br. 18, POBox 574, \\ 1000 Skopje, R. Macedonia
}

\begin{abstract}
An innovative creation process of three-cycle university education in the metrology area is presented. The case study of development of the higher education model in the field of metrology at the Ss. Cyril \&Methodius University is analyzed. The realized three-cycle university studies in metrology are fully harmonized with the Bologna principles. The structures of BSc, MSc and the joint international $\mathrm{PhD}$ study program initiated by a group of 12 European universities are shown. An international consortium of universities participated in the creation of the three level university studies in metrology. The specifics, goals, quantitative and qualitative achievements as well as the impact and contributions at the national, regional and international level of the new and innovated three-cycle metrology study programs are given and discussed.
\end{abstract}

\section{Section: RESEARCH PAPER}

Keywords: Metrology education; three-cycle study; Bologna process; international cooperation in education; metrology study programmes

Citation: Marija Cundeva-Blajer, Three-cycle University studies in metrology - An innovative development approach, Acta IMEKO, vol. 5, no. 3, article 14, November 2016, identifier: IMEKO-ACTA-05 (2016)-03-14

Section Editor: Paul Regtien, The Netherlands

Received December 25, 2015; in final form July 8, 2016; published November 2016

Copyright: (C) 2016 IMEKO. This is an open-access article distributed under the terms of the Creative Commons Attribution 3.0 License, which permits unrestricted use, distribution, and reproduction in any medium, provided the original author and source are credited

Funding: Ss. Cyril and Methodius University, Faculty of Electrical Engineering and Information Technologies

Corresponding author: Marija Cundeva-Blajer, e-mail: mcundeva@feit.ukim.edu.mk

\section{INTRODUCTION}

The cooperation in the field of education enables development of the technological collaboration. The processes initiated by the Bologna Declaration from (1999) [1], [2] for internationalization and more intensive cooperation in the higher education, through opening of the national systems of higher education, exchange of academic staff and students mobilities, gives opportunities for more intensive regional and international cooperation in engineering education.

However, the development of the metrology infrastructure at the national, regional as well as international level is predetermined by the education and training opportunities [3], [4]. Therefore the innovation of metrology education according to the Bologna Declaration [2] is not only a possibility, but also a necessity because of the demanded highest level of academic staff and research facilities at all three levels of higher education (BSc, MSc and PhD) [5].

The competitiveness of a company is based on the quality of its products and this, in turn, depends on its measurement capabilities, related to the field of metrology, defined as measurement science and its applications [6]. The metrology provides a substantial basis for fundamental research and development activities. The measuring capability is directly related to the technological level of a country and it is fundamental to the development processes of the emerging countries. Measurements have become an increasingly critical tool for national and international trade, and for removing technical barriers to global trade. Therefore, the development of a well-structured national as well as regional system of metrology is essential to support scientific progress, innovation, technology and competitiveness of enterprises [6]. The metrology plays an important role in the economical development and in the growth of industry. Hence, it is fundamental for developing countries to establish a strong national measurement infrastructure, including the development of human resources in metrology, which supports this 
economical development and the growth of the national and regional industry [3], [6].

There are different approaches in the development of the metrology studies, depending on the national regulation, current state of the art of the metrology infrastructure as well as metrology traditions [6]-[8]. The Bologna declaration of 1999 [2] has led to the process of completely reviewing the higher education system in Europe. At the end of the first Bologna decade the new two- or three-cycle degree system (Bachelor Master - Doctoral degree) has been adopted by the majority of the signatory countries. The European Credit Transfer and Accumulation System (ECTS) has triggered high interest in other major continents, e.g. in the U.S.A., while the U.S. education system is bench-marked against the European one in some studies. Also in Africa many education systems have been completely altered since the beginning of this century [8].

Metrology - the measurement science - is international and inherited in all engineering fields [3]. It is also represented at the universities in the region of South-East Europe (SEE):

1. Ss. Cyril \& Methodius University-Skopje, R. Macedonia,

2. South-Eastern European University-Tetovo, R. Macedonia,

3. University of Zagreb, R. Croatia,

4. University of Split, R. Croatia and

5. University of Prishtina, R. Kosovo.

Until 2010 at these universities knowledge in the field of metrology was gained through accredited study programmes at the first (BSc) and the second cycle (MSc) of studies according to the European Credit Transfer System (ECTS) and in line with the Bologna principles.

At the Ss. Cyril and Methodius University in Skopje, the first international cooperation for higher education reform in the field of metrology was initiated in 2005 through the EU funded project "Introduction of Two-Tier Studies of Metrology", a European project financed by the European Training Foundation, TEMPUS JEP CD 19010_2004 with partners from:

- The Netherlands (Technical University of Delft)

- Poland (AGH University-Krakow)

- Italy (Politecnico di Milano), 2005-2007 [9].

Innovated BSc courses in metrology were introduced and a completely new MSc study program in Metrology and Quality Management was accredited as outcomes of the project.

Following the process of realization of higher education according to the Bologna Declaration [2] with three cycles of studies (graduate $\mathrm{BSc}$, master MSc and doctoral $\mathrm{PhD}$ studies), the organization of a third cycle of studies in the multidisciplinary field of metrology as a need was posed [10], [11].

The mutual interest of the above mentioned SEE universities was expressed in the initiative for the creation and realization of a joint third cycle study program- $\mathrm{PhD}$ studies in metrology.

In the frame of the TEMPUS IV program, this initiative was accepted by the European Commission and the Education, Audiovisual and Cultural Executive Agency (EACEA), which financed the realization of the project 158599-TEMPUS-MKTEMPUS-JPCR „Creation of the Third Cycle of StudiesDoctoral Studies in Metrology“, [12].

In the creation of the joint $\mathrm{PhD}$ study program, beside the five above mentioned SEE universities, the following EU universities participated:
- University of Pavia, Italy,

- Braunschweig University of Technology, Germany,

- Czech Technical University in Prague,

- Graz University of Technology, Austria,

- University of Zaragoza, Spain,

- University of Gavle, Sweden,

- Superior School of Metrology, Douai, France and

- Bureau of Metrology of R. Macedonia.

Currently, at the Ss. Cyril and Methodius University in Skopje, higher education in metrology is structured according to the Bologna three cycles of study as represented in Figure 1, where ECTS denotes European Credit Transfer System.

\section{PHASE 1: INNOVATION OF BSC STUDY PROGRAM COURSES IN METROLOGY}

After the ratification of the Bologna Declaration [2] by the Parliament of R. Macedonia in 2004 [10], the process of higher education reform has intensively started in all study fields. Metrology science before the Bologna process was presented at the Ss. Cyril and Methodius University in Skopje, with the obligatory courses at the third semester of Electrical Engineering Studies through the course of Electrical Measurements, the course of Power Measurements at the study program of Power Engineering and the course of Electrical Measurements of Non-Electrical Quantities in the $9^{\text {th }}$ semester.

In 2005 new reformed BSc studies in Electrical Engineering, harmonized with the Bologna principles, were accredited. The curriculum in measurement education was innovated through some updates, but also through some completely new metrology courses given in Table 1.

The BSc study programs with the courses programs in metrology were re-accredited in 2011.

\section{PHASE 2: MSC STUDY PROGRAM IN METROLOGY AND QUALITY MANAGEMENT}

Before the Bologna process reform the metrology education at the Ss. Cyril and Methodius University at a postgraduate level was represented through the curriculum of Electrical Measurements and Materials (with several metrology courses).

In 2008 a completely new study program in Metrology and Quality Management was accredited and after some innovation in 2013 it was re-accredited.

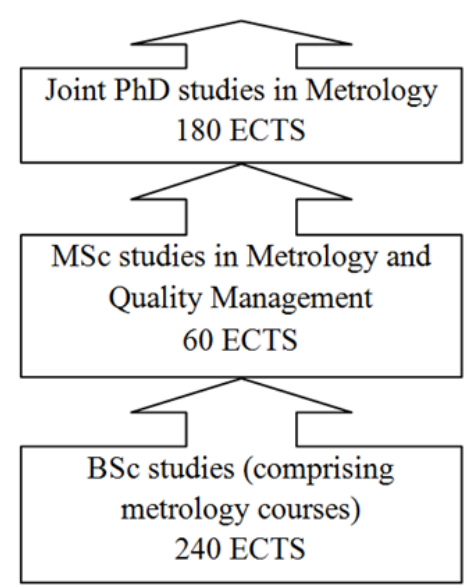

Figure 1. Three-cycle studies in metrology at the Ss. Cyril and Methodius University in Skopje according to the Bologna Declaration. 
Table 1. Metrology in BSc studies in Electrical Engineering and Information Technologies.

\begin{tabular}{lll}
\hline $\begin{array}{l}\text { Course/ } \\
\text { Study program/ } \\
\text { Electiveness }\end{array}$ & Competences & Content \\
\hline $\begin{array}{ll}\text { Electrical } \\
\text { Measurements/ }\end{array}$ & $\begin{array}{l}\text { Knowledge of methods for measurements } \\
\text { of electrical quantities, principles and } \\
\text { usages of measurement instruments. }\end{array}$ & $\begin{array}{l}\text { Basic terms and definitions in measurement techniques. Legal metrology. Static } \\
\text { and dynamic characteristics and block structures of measuring devices. Theory of } \\
\text { uncertainty, errors of repeatable and indirect measurements. Measurement } \\
\text { transducers, AC/DC transducers. Analogue instruments. Digital instruments, }\end{array}$ \\
engineering/ & & $\begin{array}{l}\text { structural elements, time interval and frequency measurements. DMM. } \\
\text { Oscilloscope. Measurement bridges. Introduction in remote measurements and } \\
\text { Obligatory }\end{array}$ \\
& measuring systems.
\end{tabular}

Electrical

Measurements of

Non-Electrical

Quantities/

Power engineering/

Elective

LabVIEW Practicum/

Power engineering/

Elective

Fundamentals of

Measurement

Systems/

Computer

engineering/

Elective

Computerized

Measurements/

Computer

engineering/

Elective

Power Measurements

Power engineering/

Obligatory

Process

Measurements/

Automatics, system

engineering /

Elective

Telecommunication Measurements/

Telecommunications/

Elective

Principles of Quality Control/

Automatics, system engineering /

Elective
Knowledge on measurement systems and elements of the measurement systems, basic sensor technologies, methods for measurement of non-electrical quantities by electrical procedures, process monitoring systems, application of modern virtual instrumentation and computer techniques for measurements

Basic knowledge about LabVIEW program, interfacing of measurement devices with PC, analysis and data acquisition of measurement data. Programming of SCADA systems, communication with programmable logic controllers.

Knowledge of basic methods for measuring the electrical and nonelectrical quantities. Introduction to the principles of analogue and digital measuring instruments.

Capability for development and support of computer-based measurement systems and measurement data transmission. Design and realization of information measurement systems.

Knowledge for measuring methods and instrumentation for measurements in electrical networks.

Development of measurement systems applicable in industrial processes.

Capability to work with measurement devices and measurement information systems in telecommunication

Introduction to electrical measurements of non-electrical quantities. Application of measurement systems. Elements of a measurement system. Choice of a proper measurement device or system. Basic sensor technologies (resistance, capacitance, magnetic sensors, Hall effect sensors, piezoelectric transducers, strain gauges, piezo-resistive sensors, optical sensors, ultrasound sensors, nuclear sensors). Micro-sensors and special sensor technologies. Smart sensors. Measurement noise. Measurement signals conditioning. A/D conversion. Telemetry. Measurement of mechanical quantities (dimensions, translation, translation and rotation velocity, acceleration, mass, force, torque, pressure). Measurement of sound, noise and vibrations. Measurement of speed, flow and fluid level. Humidity measurement. Temperature measurement. Radiation measurement. Systems for monitoring and process measurements. Modern virtual instrumentation and computer techniques for measurement of nonelectrical quantities.

Virtual instrumentation and LabVIEW. LabVIEW environment. Declaration of variables, matrices and arrays. Cycles, state machines, clusters and arrays. Graphical user interface. File generation, data acquisition, measurement and signal generation. LabVIEW advanced features. Measurement control systems in LabVIEW. Communication interfaces in LabVIEW. Distributed measurement systems in LabVIEW.

Basic concepts and definitions in the measurement techniques. Static and dynamic characteristics of measurement devices. Fundamentals of uncertainty, errors in indirect measurements. Basic characteristics of analogue and digital measuring instruments. Sensors and converters. Classification of measurement sensors. Introduction to resistive, inductive and capacitive sensors for measurement of various physical quantities. Signal conditioning and basic configurations of measurement circuits.

Architecture of computer elements for data acquisition. Measurement signal conditioning. $A / D$ and $D / A$ conversion. Standard interfaces, serial and parallel. Virtual measurement systems. Graphical programming and introduction to LabVIEW. Work with variables, their declaration, cycles, areas and clusters. User interface, measurement data recording and display. Examples of measurement information and measurement controlled PC systems.

Voltage and current measuring transformers, applications and errors. Methods for measuring one-phase and three-phase power and power factor. Electronic and digital watt-meters. Digital electricity meters, principles and errors. Introduction to remote measurements and measurements data transmission. Grounding grid measurements touch and step voltages, earth specific measurements. Power quality measurements.

Introduction to measurement systems in processes and their role in automated systems. Classification of sensors and transducers. Transmission of measurement data, voltage and current loops, industrial communication protocols. Sources of errors in processes measurement systems, electromagnetic interferences, active and passive shields. Microprocessor based measurement systems, smart sensors and MEMS. Materials and technologies of fabrication of smart sensors.

Measurement role in quality control of telecommunication equipment. Programmable measurement devices. Microprocessors and measurement applications. Interfaces. Measurement data acquisition. Frequency and period measurements. High frequency power measurements. Measurement errors in high frequency power measurements. Measurements of non-linear distortions. Pulse generator. Signal analyzer. Spectral analyzer. Logic analyzer. Digital storage oscilloscope.

History and development of quality control. Introduction to the basic terms. The ISO 9001 quality standard. Total quality management. Mathematical models for quality control, review of basic terms and concepts. Introduction to diagrams for quality control. Special control diagrams for attributes and variables in quality control. Specification of limit values, tolerance and other techniques. Process control. Industrial experiments. Design of robust systems. 
The objectives of the MSc study program in Metrology and Quality Management are to educate masters of sciences in the field of metrology and quality management who will be capable to work in:

- different companies from industry

- companies from the power sector

- industrial and scientific laboratories where precise measurements are an important factor in the production

- companies which are selling and servicing measurement equipment and instrumentation

- the laboratories which are part of the metrological infrastructure, as well as

- all others companies where measurements and measurement systems are part of their production process.

The study program produces engineers who can work in different sectors and industries, where metrology is a pillar for their successful development.

The future masters can work also in scientific institutions and universities, research centres, different laboratories, etc.

The recent accredited MSc courses in metrology are:

1. Principles of metrology and quality management;

2. Uncertainty in measurement and calibration;

3. Sensors and measurement transducers;

4. Microprocessor-based programmable instrumentation;

5. Legal and industrial metrology;

6. Power systems measurements;

7. Processing and transmission of measurement data;

8. Computerized measurement systems and virtual instrumentation;

9. Digital signal processing;

10. Measurement and control systems;

11. Environmental monitoring;

12. Computer and numerical methods in metrology;

13. Quality assurance and quality control;

14. Project management;

15. Nanometrology and standardization;

16. Techniques for non-destructive testing;

17. Nanomaterials and nanostructures;

18. Metrology of geometrical quantities.

The innovation and creation of the BSc as well as the MSc courses and curricula were performed through the EU project "Introduction of Two-Tier Studies of Metrology" and by active support of the:

- Technical University of Delft, The Netherlands,

- AGH University, Krakow, Poland and

- Politecnico di Milano, Italy [9].

\section{PHASE 3: CREATION OF PHD STUDY PROGRAM IN METROLOGY}

The development of the metrology is tightly connected to the development of the industrial production, technical cooperation and trade. In the region of South-Eastern Europe the development of metrology was behind the needs of the industry, trade and society [1], [3], [5]. The metrological infrastructure and especially the national metrological institutes lack highly educated staff which would be the carriers of the further development [3]. Therefore, in 2010, an EU initiative was launched by three South-East European (SEE) countries jointly to create a study program at doctoral level in metrology.
The countries which jointly developed the joint $\mathrm{PhD}$ study program are R. Macedonia, R. Croatia and R. Kosovo, i.e. the universities:

- Ss. Cyril and Methodius University in Skopje

- University of Zagreb

- University of Split

- University of Prishtina

- South-Eastern European University in Tetovo.

Beside in the three above mentioned countries, there is also a lack of staff in the field of metrology in the other Balkan countries (Greece, Serbia, Bulgaria, Bosnia and Herzegovina, Montenegro, Albania etc.) [5].

By taking into account that metrology is a science represented in all technical disciplines and activities, the candidates which would accomplish the doctoral studies would have wide opportunities for application of their knowledge through activities in numerous fields through problems solving in the industry, health and food sector, environmental protection, energy, transportation and trade sector. So, conditions for development of the metrological infrastructure for the above mentioned areas were created.

The wider goals of the joint $\mathrm{PhD}$ education are:

- Enhancement of the quality and relevance of the higher education in metrology in Macedonia, Croatia and Kosovo.

- To upgrade the capacities of the SEE universities for international cooperation and for permanent modernisation.

- Orientation of the SEE universities to offer high quality education in metrology for the necessary industrial development and economic co-operation with the EU.

- To intensify the co-operation of the academic staff of the SEE and EU universities.

The specific objectives are:

- Harmonisation of the studies in metrology in the three cycle degree system according to the Bologna process.

- Creation of $\mathrm{PhD}$ studies in metrology at the SEE universities.

- Development of new courses and modernisation of the existing ones.

- Upgrading of laboratories for practical training to $\mathrm{PhD}$ students in metrology.

- Establishment of a joint $\mathrm{PhD}$ study program in metrology among the SEE universities.

- Transfer of knowledge and experience in the area of metrology.

The creation of the joint study program in metrology was realized through set of joint activities of the SEE universities, such as:

1. Elaboration of a new regulation on the third cycle of $\mathrm{PhD}$ studies in metrology harmonised with the Bologna principles.

2. Elaboration and adoption of the joint study programme for PhD studies in metrology.

3. Creation and maintenance of a web-page of the $\mathrm{PhD}$ studies in metrology (www.tempus-metrology.ukim.edu.mk)

4. Promotion of the PhD studies in metrology.

5. Development of the content and teaching materials of the new and modernized courses for $\mathrm{PhD}$ studies in metrology.

6. Acquisition of laboratory equipment. 
7. Elaboration of an agreement for the joint $\mathrm{PhD}$ study program among the SEE universities.

8. Training of academic staff of the SEE universities by the EU universities through study visits, workshops and invited lectures.

9. Enrolment of $\mathrm{PhD}$ students at the study programme of metrology and students exchange.

10. Dissemination of the results and experience from the creation of joint $\mathrm{PhD}$ study program

11. Insurance of sustainability of the PhD study program.

These activities were jointly and internationally realized.

In Figures 2 and 3 the joint study visit to the laboratories of the Braunschweig University of Technology and the Swedish National Metrology Institute SP in Boras are shown, respectively. pillars:

The joint PhD study program in metrology consists of four

- ICT in metrology;

- Instrumentation, industrial metrology, quality science;

- Metrology for life and society;

- Scientific metrology.

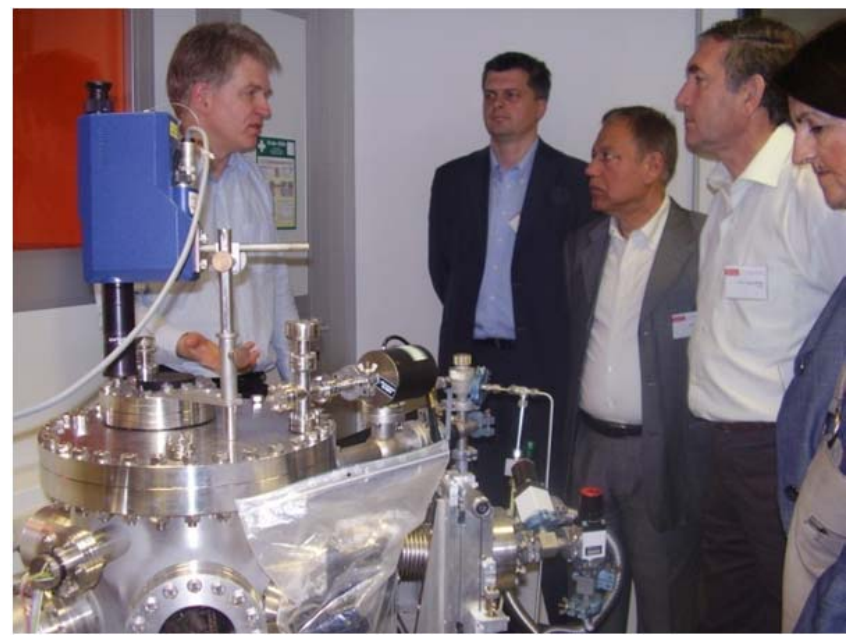

Figure 2. Joint study visit of SEE academic staff to laboratories of the Braunschweig University of Technology.

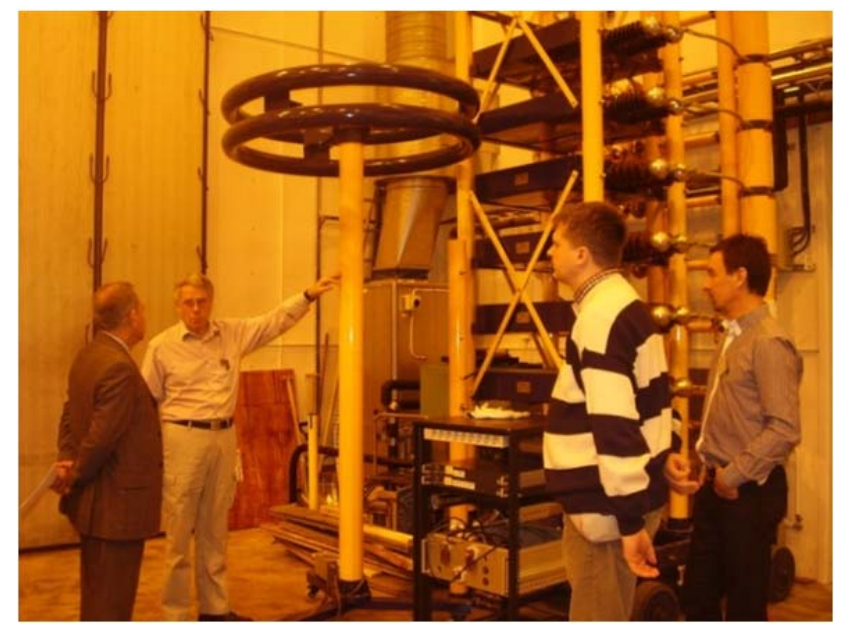

Figure 3. Joint study visit of SEE academic staff to laboratories of the Swedish National Metrology Institute SP-Boras.
The pillars are addressing the most challenging areas in contemporary metrology. Each of these pillars comprises several courses given in Table 2 .

The courses are lectured by at least two professors: one from the SEE universities and one from the EU universities. The students choose four of the elective courses for their curriculum and choose a supervisor from the SEE universities and a co-supervisor from the EU universities for the $\mathrm{PhD}$ research. The program is realized by sharing academic staff, laboratories facilities and through a common student's pool.

The student mobility is one of the emphasised components in the realization of the joint $\mathrm{PhD}$ program in metrology. The mobility is implemented through joint lectures and workshops, $\mathrm{PhD}$ student conferences and presentations and study visits for accomplishment of the $\mathrm{PhD}$ research. This concept of realization of the joint $\mathrm{PhD}$ program implies not only educational cooperation, but also scientific bonding through joint research projects and exchange of researchers.

The results of the joint $\mathrm{PhD}$ study program in metrology are the creation of high-qualified professionals and researchers with the following general competences:

- capability of research and development of solutions;

- documenting the scientific researches;

- working in interdisciplinary scientific research teams;

- analysis of scientific and expertise problems;

- application of the knowledge into praxis;

- application of scientific research procedures and methods;

- possibility of systematization of knowledge;

- capability of generation of new ideas and solutions;

- knowledge of scientific ethics;

- presentation of scientific research results.

Table 2. PhD Study Program in Metrology.

\begin{tabular}{|c|c|}
\hline Pillars & Courses \\
\hline \multirow{5}{*}{$\begin{array}{l}\text { ICT in } \\
\text { Metrology }\end{array}$} & 1. Data acquisition and data processing \\
\hline & 2. Sensors and sensor networks \\
\hline & 3. Applicative software for metrology \\
\hline & 4. Modelling and numerical methods in metrology \\
\hline & 5. Knowledge discovery and data mining \\
\hline \multirow{5}{*}{$\begin{array}{l}\text { Instrument } \\
\text { ation, } \\
\text { Industrial } \\
\text { Metrology }\end{array}$} & 1. Signal conditioning \\
\hline & 2. Complex monitoring and control systems \\
\hline & 3. Metrology for energy \\
\hline & $\begin{array}{l}\text { 4. RF Measurements and metrology in } \\
\text { telecommunications }\end{array}$ \\
\hline & 5. Diagnostics, NDT and quality control \\
\hline \multirow{4}{*}{$\begin{array}{l}\text { Metrology } \\
\text { for life and } \\
\text { society }\end{array}$} & $\begin{array}{l}\text { 1. Metrology for life sciences-environmental } \\
\text { monitoring }\end{array}$ \\
\hline & $\begin{array}{l}\text { 2. Metrology for chemistry, biochemistry and food } \\
\text { quality and safety }\end{array}$ \\
\hline & 3. Electromagnetic fields, electrical safety EMC \\
\hline & $\begin{array}{l}\text { 4. Sensor systems for biomedical measurements and } \\
\text { medicine }\end{array}$ \\
\hline \multirow{3}{*}{$\begin{array}{l}\text { Scientific } \\
\text { Metrology }\end{array}$} & 1. Quantum metrology and nano-metrology \\
\hline & $\begin{array}{l}\text { 2. Primary standards, precise measurements and } \\
\text { calibration }\end{array}$ \\
\hline & 3. Metrology of mechanical quantities \\
\hline
\end{tabular}


The specific competences of the doctors of science in the scientific field of metrology are:

- expert knowledge in the areas studied through the courses of the study program in metrology,

- management of scientific and metrology researches,

- design of new products and technologies,

- management and design of metrology processes,

- capability of management of the functions in a company and their integration through metrology,

- generation of innovative metrology approaches,

- solving practical problems by using scientific metrology methods and procedures,

- activities in metrology consulting services connected to design and engineering of products/processes,

- capability of relating theoretical knowledge and practical application of metrology in the engineering processes in the companies,

- capability of application of research methods in metrology praxis.

By accomplishment of the doctoral studies in metrology, the doctors of sciences in the field of metrology are competent for following job positions:

- Academic staff in higher education institutions;

- Researchers in research centers;

- Researchers in R\&D centers in the industry;

- Researchers and managers in the metrological infrastructure and the national metrology institutes.

\section{QUANTITATIVE AND QUALITATIVE ANALYSIS OF THE REALIZED THREE-CYCLE UNIVERSITY STUDIES IN METROLOGY}

Some of the metrology courses in the undergraduate studies in the area of electrical engineering are obligatory as given in Table 1. So, all the students enrolling the third semester also enrol the obligatory courses in metrology. The average number of students in the third semester at the Faculty of Electrical Engineering and Information Technologies at the Ss. Cyril and Methodius University in Skopje in the last ten years is app. 200. The success rate of the students who successfully pass the final exam is very high (in average $90 \%$ ). The number of students, who enrol the elective BSc courses in metrology, is variable, because the pool of students varies depending on the study program and the semester in the curriculum. For example, the average number of students enrolling the course of Power Systems Measurements is app. 70 in the last five years. However, the interest for some specialized courses, like Computerized Measurement Systems or Telecommunication Measurements, is low, i.e. app. 6 students per semester. Still, the success rate of this courses is very high (almost $100 \%$ ), because of the small groups, the individual approach and the possibility for intensive laboratory praxis. The students exchange is not so developed at BSc level, but this opens future possibilities, especially through the EU Erasmus program. The academic exchange is done through lectures by visiting professors, appr. 2-3 per semester (Figures 4 to 6).

Since the accreditation of the MSc study program in Metrology and Quality Management in 2008 at the Ss. Cyril and Methodius University in Skopje,33 students have enrolled this

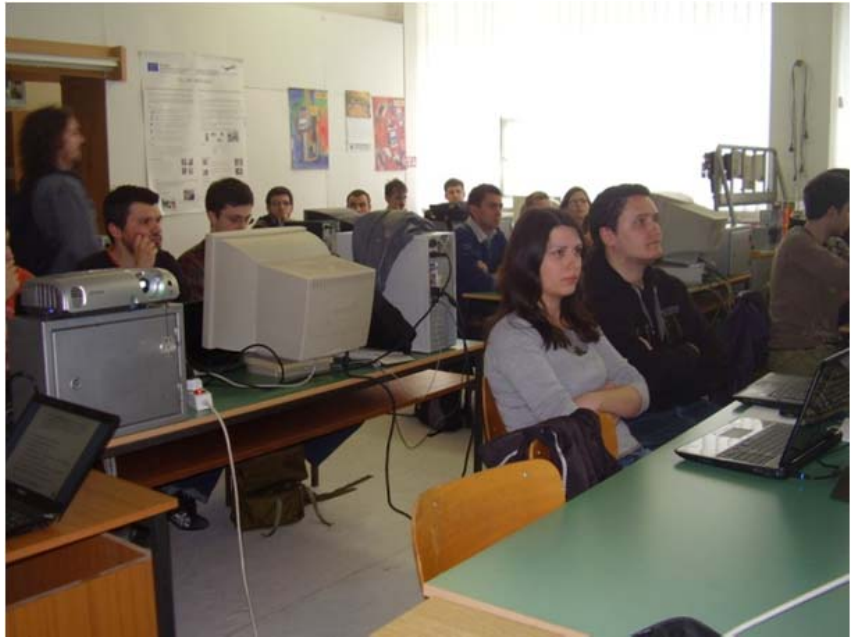

Figure 4. Joint lectures for PhD students in metrology.

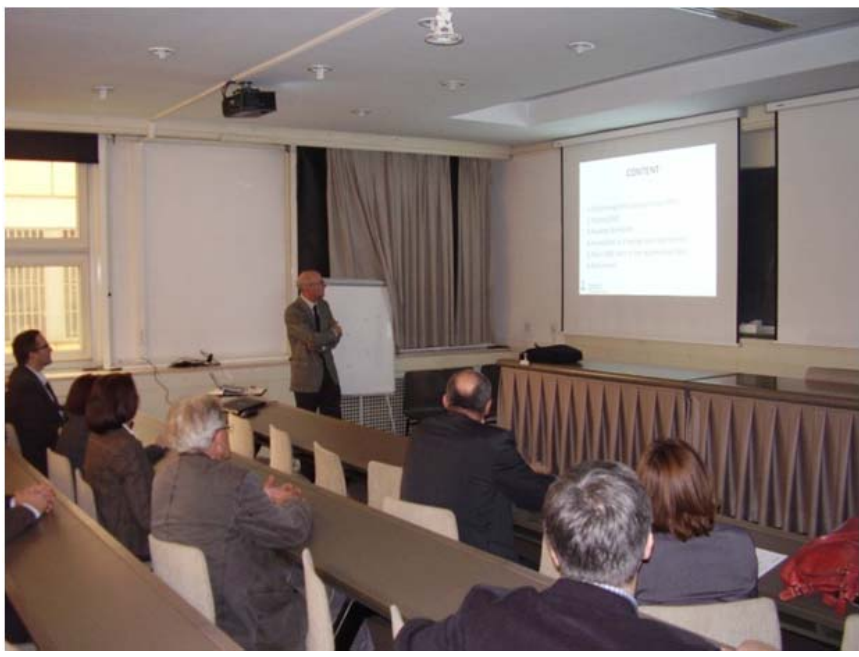

Figure 5. EU training of the SEE academic staff (professors) involved in the joint PhD study program in metrology.

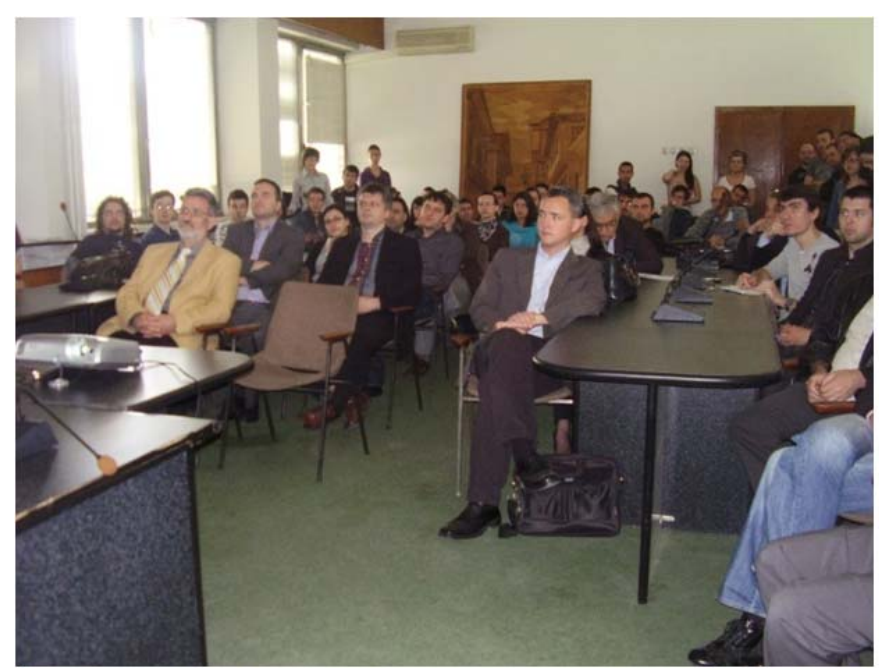

Figure 6. Joint lectures for PhD students in metrology open for the wider audience-with participation of metrologists from the industry and other metrology stake holders. 
study program as given in Table 3. Most of them (70\%) are with accomplished BSc degree in electrical engineering. The other candidates are with BSc degrees in physics, chemistry, and mechanical engineering, technology engineering or similar. Up to now, 16 students have accomplished their master thesis. At MSc level the success rate is lower than at BSc level, which can be concluded from the data in Table 3 . The main reason is that the candidates are mostly part-time students and are already employed. The topics of the MSc theses are mainly in the metrology of electromagnetic quantities and metrology of energy and power, which is to be expected considering the BSc background of the students (e.g. "A Contribution to the Metrology Infrastructure in R. Macedonia-National Standard of Electrical Energy and Power"). However, some of the MSc theses are in other scientific areas, like flow and volume metrology (e.g. "Elaboration of National Standard of Mass Flow"), length metrology, mass metrology or some other specialized fields like environmental metrology, metrology for information security or metrology for air traffic security. The exchange of students at MSc is more intensive, especially during the life-time of the two TEMPUS projects in 2007-2008 and from 2010-2013. In the frame of the projects app. $10 \mathrm{MSc}$ students have realized study stays at the partner universities. Also, app. 10 lectures were given by visiting professors from the partner universities. Two students have accomplished the experimental part of their MSc theses in the laboratories of the partner universities.

After the end of the TEMPUS projects, the students mobilities are enabled through the EU Erasmus program (in both directions), or through other international or bilateral scientific programs.

Since the accreditation of the $\mathrm{PhD}$ studies in Metrology in 2013, six students have enrolled the study program, only at the Ss. Cyril and Methodius University in Skopje. The number of students is satisfactory, bearing in mind that it is the third cycle and the specifics of the field. The students are with interdisciplinary background (MSc in electrical engineering, mechanical engineering, physics...). Until now, no candidate has accomplished the $\mathrm{PhD}$ title. All the students are part-time students already employed in the industry or metrology infrastructure. Depending on the year of enrolment they have different success rate in the accomplishments of the $\mathrm{PhD}$ courses and the scientific progress in their PhD research. This is still an early stage of the $\mathrm{PhD}$ study program to make more specific conclusions on the success rate. Since the accreditation of the $\mathrm{PhD}$ study program in metrology, which was accomplished at the end of the EU TEMPUS-158599 project as a main outcome of the project, the students and professors

Table 3. Annual data on MSc in Metrology and Quality Management.

\begin{tabular}{cccc}
\hline $\begin{array}{c}\text { Academic } \\
\text { year }\end{array}$ & $\begin{array}{c}\text { Number of } \\
\text { enrolled students }\end{array}$ & $\begin{array}{c}\text { Number of } \\
\text { accomplished MSc }\end{array}$ & $\begin{array}{c}\text { Success } \\
\text { rate [\%] }\end{array}$ \\
\hline 2008 & 12 & 7 & 58.33 \\
2009 & 4 & 4 & 100.00 \\
2010 & 3 & 1 & 33.33 \\
2011 & 4 & 1 & 25.00 \\
2012 & 2 & 2 & 100.00 \\
2013 & 4 & 1 & 25.00 \\
2014 & 1 & 0 & 0.00 \\
2015 & 3 & 0 & 0.00 \\
\hline
\end{tabular}

mobilities are enabled through other programs like the EU Erasmus program (in both directions), or through other international or bilateral scientific programs.

The international dimension of the joint $\mathrm{PhD}$ study program in metrology can be seen in Table 4, where the academic staff contribution of each of the partner universities is displayed.

\section{CONTRIBUTION, INTERNATIONAL IMPACT AND SUSTAINABILITY OF THE THREE-CYCLE STUDIES IN METROLOGY}

The creation of the three-cycle university studies in metrology and the joint realization by the SEE and the EU universities potentially contribute to enhancement of the whole scientific and technical cooperation among these countries. The up-to-date experience shows that the results of this cooperation such as upgrading the level of the academic staff, upgrading the laboratories' facilities or enhancement of exchange of knowledge, is not limited only to the formal university studies. It broadens also positive influence on life-long learning, professional development, and training and generally on the scientific work. It is achieved through mobilities of the academic staff, inclusion of professors from other universities, professionals from the NMIs, metrological infrastructure and industry. Invited lectures, workshops in metrology are open to all interested institutions and professionals.

The network of the $5 \mathrm{SEE}$ universities and $7 \mathrm{EU}$ universities is extended to other universities, national metrology institutes, laboratories performing testing end calibrations and other research institutions in the region, but also wider in Europe.

The realization of the joint $\mathrm{PhD}$ study program developed a common language among the participants in the project, initiation and launching of novel joint ideas for further scientific and metrology cooperation.

This is a guarantee of the sustainability of the established three-degree study programs in metrology and for further enhancement of international impact.

\section{CONCLUSIONS}

The paper presented an original process of creation of three-cycle university education in the area of metrology. The specifics, qualitative and quantitative achievements and

Table 4. Academic staff of the PhD study program in metrology.

\begin{tabular}{lc}
\hline University & $\begin{array}{c}\text { Number of } \\
\text { professors engaged }\end{array}$ \\
\hline Ss. Cyril and Methodius University in Skopje & 11 \\
South Eastern European University in Tetovo & 1 \\
University of Zagreb & 5 \\
University of Split & 2 \\
University of Prishtina & 1 \\
Czech Technical University in Prague & 2 \\
University of Pavia & 1 \\
University of Zaragoza & 1 \\
Braunschweig University of Technology & 1 \\
University of Gavle & 1 \\
Graz University of Technology & 1 \\
\hline
\end{tabular}


contribution of the innovated and new study programs were given.

The education cooperation through realization of joint study programs, such as presented in the paper, extends also the international scientific, technical and metrological cooperation.

The jointly educated staffs represent a bridge for realization and further development of education, scientific, technical and metrological cooperation among the universities, metrology infrastructure and countries.

Education cooperation through the university programs in metrology is a form which is contributing to the joint technological and metrology infrastructure development.

\section{REFERENCES}

[1] M. Cundeva-Blajer, "Development of Three-Cycle University Studies in Metrology", Proc. of 21 st IMEKO World Congress, Aug. 30-Sept.4, 2015, Prague, Czech Republic, pp. 42-47.

[2] The Bologna Declaration, 1999.

[3] L. Arsov, M. Cundeva-Blajer, "Establishing a Metrological Infrastructure and Traceability of Electrical Power and Energy in the R. Macedonia", ACTA IMEKO, Volume 2, No. 2, December 2013, pp. 86-90.

[4] Education, Audiovisual and Culture Executive Agency, 2012 „Overview of the Higher Education Systems in the Tempus Partner Countries: Southern Mediterranean, A Tempus Study“, No 14, EACEA, Brussels, November 2012.

[5] L. Arsov, M. Cundeva-Blajer, "Internationalization of the $\mathrm{PhD}$ Education in Metrology", Internationalisation In Higher Education: Evaluating Concepts, Challenges And Strategies IHE
2013, PRADEC Interdisciplinary Conf. Proc., Vol. 2, Prague, Czech Republic, Paper No. 7, 25-26 April, 2013.

[6] G. M. Rocha, R. P. Landim, "The Brazilian Experience in the Development of Human Resources in Metrology", Proc. of 20th IMEKO World Congress, Sept. 9-14, 2015, Busan, South Korea, pp. TC1-O2.

[7] T. Gordiyenko, A. Gaber, "Occupational Education of Specialists in Field of Metrology and Instrumentations in Ukraine", Proc. of $21^{\text {st }}$ IMEKO World Congress, Aug. 30-Sept. 4, 2015, Prague, Czech Republic, pp. 56-61.

[8] L. P. Van Biesen, J. L. Kaindu, J. M. Boyokame, "New Tools for Training the Skills of Students in the Process of the Academisation in the Education of Engineering Degrees: A Testimony with Application to Metrology from the Democratic Republic Congo", Proc. of $21^{\text {st }}$ IMEKO World Congress, Aug. 30-Sept. 4, 2015, Prague, Czech Republic, pp. 76-78.

[9] V. Dimcev, M. Cundeva-Blajer et. al. "Introduction of Two-Tier Studies of Metrology", EU project financed by the European Training Foundation TEMPUS JEP CD 19010_2004, 20052007 ETF Final Report, Skopje, 2008.

[10] Higher Education Law, Official Gazette of R. Macedonia No. 35, 2008.

[11] Rulebook on the Conditions, Criteria and Rules for Enrolment and Studying at the Third Cycle of Studies-Doctoral Studies, Ss. Cyril and Methodius University-Skopje, University Gazette, No. 150, 2010.

[12] L. Arsov, M. Cundeva-Blajer et. al. "Creation of the Third Cycle Studies-Doctoral Studies in Metrology”, EU TEMPUS IV Joint Multi-country Project, 2010-2013, EACEA Final Project Report, Skopje, 2013. 